\title{
Geriatric challenges in the new coronavirus disease-19 (COVID-19) pandemic: A systematic review
}

\author{
Masoumeh Mohamadi ${ }^{1}$, Azadeh Goodarzi*1 (D) Armin Aryannejad ${ }^{2}$, Nima Fattahi ${ }^{2}$, Mahtab Alizadeh-Khoei ${ }^{3}$, Shahnaz \\ Miri ${ }^{4}$, Hamidreza Hekmat ${ }^{5}$, Moloud Payab ${ }^{6}$, Mohammad Bodaghabadi ${ }^{7 *}$ (D)
}

Received: 17 May 2020

Published: 17 Sep 2020

\section{Abstract}

Background: During the COVID-19 pandemic, elderly individuals (with the chronological age of 65 years and above) are more susceptible to the SARS-CoV-2 infection complications due to altered immune system response and the higher rate of underlying comorbidities. A vast majority of mortalities are reported in elderly patients; thus, this study aimed to evaluate complications of COVID-19 in elderly patients.

Methods: A systematic review was conducted according to MOOSE guidelines. Science Direct, Google Scholar, Scopus, PubMed databases were searched for published articles related to COVID-19 in the elderly up to March 26, 2020. Search MeSh terms included "Severe acute respiratory syndrome coronavirus 2", "2019-nCoV", "SARS-CoV-2", "comorbidity", "elderly", and "geriatrics".

Results: In total 1360 potentially relevant articles were screened, of which 35 were relevant and their full texts were considered for the review. Organ damages to the pulmonary system, cardiovascular, liver, and renal system are more prevalent in the elderly with SARS-CoV-2 infection. As the chance of multiorgan involvement is more common among elderly patients, preventive, multidisciplinary, and holistic evaluations are essential to reduce disease consequences.

Conclusion: More attention needs to be paid to elderly individuals in the quarantine. Social contact should be made and maintained through online facilities, media, and phone calls to ensure patients' mental health during this stressful situation. Also, they should be provided with enough food and medications by their families or friends. Also, providing social and volunteer services might play an important role in the mental health of those patients who have no social network.

Keywords: Severe acute respiratory syndrome coronavirus 2, 2019-nCoV, COVID-19, Coronavirus disease 2019, Comorbidities, Elderly, Geriatric, Systematic review

Conflicts of Interest: None declared

Funding: None

*This work has been published under CC BY-NC-SA 1.0 license.

Copyright $\odot$ Iran University of Medical Sciences

Corresponding authors: Dr Mohammad Bodaghabadi, mohammad_bodaghabadi@razi.tums.ac.ir Dr Azadeh Goodarzi, goodarzi.a@iums.ac.ir

\footnotetext{
1. Department of Dermatology, Rasoul Akram Hospital, Iran University of Medical Sciences, Tehran, Iran

2. Non-Communicable Diseases Research Center, Endocrinology and Metabolism Population Sciences Institute, Tehran University of Medical Sciences, Tehran, Iran

3. Clinical Gerontology \& Geriatric Department, Ziaeian Hospital, Medical School, Tehran University of Medical Sciences, Tehran, Iran

4. Department of Neurology, MedStar Georgetown University Medical Center, Washington, D.C., United States

5. Department of Cardiology, Ziaeian Hospital, International Campus, Tehran University of Medical Sciences, Tehran, Iran

6. Obesity and Eating Habits Research Center, Endocrinology and Metabolism MolecularCellular Sciences Institute, Tehran University of Medical Sciences, Tehran, Iran

7. Department of Geriatric Medicine, Ziaeian Hospital, Tehran University of Medical Sciences, Tehran, Iran
}

\section{$\uparrow$ What is “already known” in this topic:}

The novel Coronavirus pandemic has presented the world with a global crisis. The elderly with preexisting chronic illnesses, such as hypertension, renal failure, cerebrovascular diseases, respiratory diseases, cancer, cardiovascular diseases, and diabetes, are more prone to the risk of mortality. A vast majority of mortalities are reported in elderly patients. This study aimed to evaluate complications of COVID-19 in elderly patients.

\section{$\rightarrow$ What this article adds:}

In total 1360 potentially relevant articles were screened, of which 35 met the inclusion criteria. Organ damages to the pulmonary system, cardiovascular, liver, and renal system are more prevalent in the elderly with SARS-CoV-2 infection. As the chance of multiorgan involvement is more common among elderly patients, preventive, multidisciplinary, and holistic evaluations are essential to reduce disease consequences. Social contact should be made through online facilities, media, and phone calls to ensure patients' mental health during this stressful situation. 
Cite this article as: Mohamadi M, Goodarzi A, Aryannejad A, Fattahi N, Alizadeh-Khoei M, Miri Sh, Hekmat H, Payab M, Bodaghabadi M. Geriatric challenges in the new coronavirus disease-19 (COVID-19) pandemic: A systematic review. Med J Islam Repub Iran. 2020 (17 Sep);34:123. https://doi.org/10.47176/mjiri.34.123

\section{Introduction}

The new Coronavirus disease (COVID-19) was initially diagnosed in Wuhan, China. The new Coronavirus, named severe acute respiratory syndrome Coronavirus 2 (SARSCoV-2), spreads person-to-person (1). COVID-19 has been known as a pandemic as the World Health Organization (WHO) announced earlier in March 2020 (2). The number of confirmed cases of SARS-CoV-2 infection by real time RT-PCR test has reached about 10 million patients around the world (https://www.worldometers.info/ coronavirus/). The most common clinical characteristics of COVID-19 include fever, cough, fatigue, myalgia, headache, and gastrointestinal symptoms $(3,4)$. Leukopenia and raised C-reactive protein (CRP) levels are the most common findings among the confirmed cases $(5,6)$.

Superficial glycoprotein spike (S) in the new Coronavirus plays a crucial role in the cell attachment process, which interacts with the human ACE2 receptor. SARSCoV-2 has been found to enter cells through this mechanism in recent studies $(7,8)$. The ACE2 gene is highly expressed in the lungs, gastrointestinal tract, and the podocytes, and the proximal tubule segment in kidneys, which makes these organs potential receptor sites for SARS-CoV-2 (9). These receptors are also expressed in the cardiac myocytes, so they could lead to direct injury of the myocytes by interacting with SARS-CoV-2 (10). As the studies have found these mechanisms of action, COVID-19 can damage multiple organs. In elderly patients, these damages could be more severe and lethal. Most of the elderly patients with severe COVID-19 pneumonia had a history of underlying diseases, including cardiovascular diseases, respiratory diseases, cerebrovascular diseases, liver disease, renal dysfunction, diabetes, and malignant tumors (11). Apart from pneumonia, some patients with SARS-CoV-2 infection develop major organ failures (12). The elderly individuals with COVID-19 are confronted with the most threats and challenges and as the disease is more severe and lethal in elderly patients, we aimed to discuss complications of COVID-19 in elderly patients in this review.

\section{Methods}

\section{Search strategy and data collection}

This systematic review was performed according to MOOSE guidelines with a systematic research process. Studies were identified by searching the databases, including Science Direct, Google Scholar, Scopus, and PubMed up to and including March 30, 2020. The world's leading websites concerned with public health, such as the World Health Organization (WHO) and the Centers for Disease Control and Prevention (CDC), have also been used to obtain the latest statistics and information and increase coverage of included articles and ensure literature saturation. A combination of the following Entree, Mesh terms, and appropriate keywords were used to search the title, abstract, or full-text articles: "Severe acute respiratory syndrome coronavirus 2", "COVID-19", "2019-nCoV", "SARS-CoV-2", "coronavirus", "comorbidity", "elderly", and "geriatrics".

\section{Inclusion criteria}

All studies focusing on clinical characteristics and complications of SARS-CoV-2 were eligible for inclusion. All reference lists of relevant studies were screened to identify any missing publications. All studies were independently screened by the review authors based on their titles and abstracts. The full-text of articles potentially suitable for the review were obtained to assess relevance based on the inclusion/exclusion criteria. A total of 1360 relevant studies were screened. After reading abstracts, repetitive studies were removed. In the next step, irrelevant studies that did not include elderly population data or those with unconfirmed SARS-CoV-2 were excluded. Inclusion criteria were studies with (1) elderly population (65 years and older); (2) addressing infection with 2019-nCoV; and (3) studies written in English. The search results were limited to publications in English and excluded abstracts from conferences and commentaries. A total of 104 full-text articles were assessed for eligibility, out of which 35 articles were selected as relevant, and their full-texts were considered for the review.

\section{Data extraction}

Data were extracted independently from included trials by 2 authors according to a predefined data extraction sheet. The extracted data included (a) general information (author, title, publication year, type of study and location), (b) participants (sample size, sex, and age), (c) outcomes (most common symptoms and comorbidities).

Any disagreements in the assessment of data were resolved by discussion between the 2 authors, and consultation was made with a third reviewer in case of any discrepancies. The whole process of study selection is summarized in the Preferred Reporting Items for Systematic Reviews and Meta-Analyses (PRISMA) flow diagram (Fig. 1).

\section{Results}

\section{Elderly individuals and COVID-19}

Elderly patients are more susceptible to the severe infection with SARS-CoV-2 than younger patients due to generally weaker immune response and the presence of comorbidities and underlying diseases. As a result, the management of elderly patients with COVID-19 requires much more caution than younger patients. In a recent meta-analysis, the most common symptoms in middle-aged and elderly patients with COVID-19 were cough (70.5\%), fever $(64.1 \%)$, and fatigue $(44.5 \%)$. In the critically ill patients who needed an ICU admission, the most common 


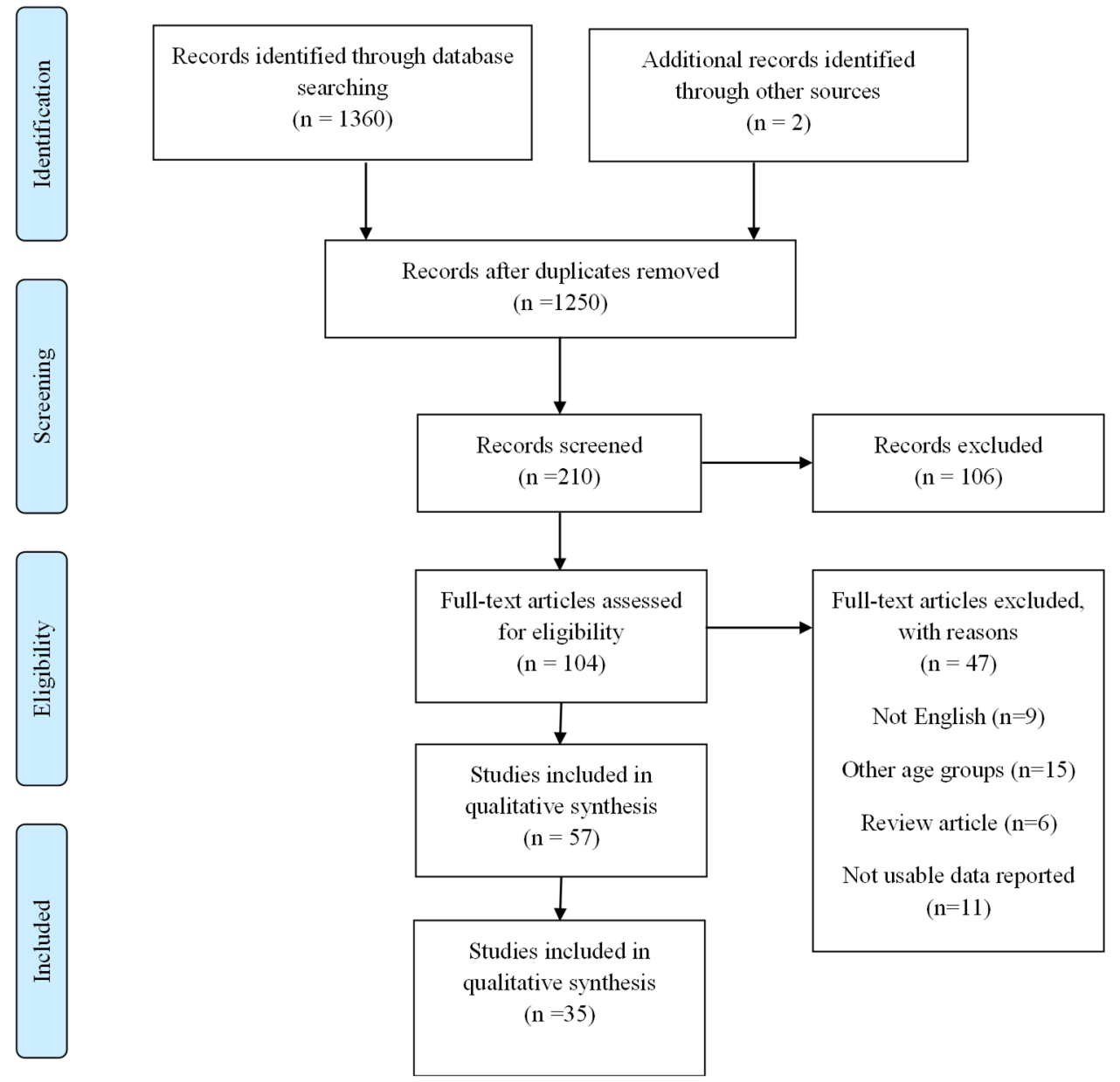

Fig. 1. PRISMA flow diagram of the literature search strategy

symptoms were cough (67.2\%), fever (62.9\%), and dyspnea $(61.2 \%)(13)$.

A recent study of 56 patients compared elderly patients to middle-aged and younger patients with COVID-19 pneumonia. Based on that study, the pneumonia severity index (PSI), multilobar involvement on chest CT scans, the prevalence of acute respiratory distress syndrome (ARDS), and the level of CRP were significantly higher in the elderly than the younger patients. Lymphocytes were, however, significantly lower in elderly patients. In this study, the rate of acute injury to the heart, kidneys, and liver and also the prevalence of secondary bacterial pneumonia were higher in the elderly group (14). In another study, 124 elderly patients with confirmed diagnosis of COVID-19 in the outpatient setting were evaluated. Of them, 92\% had bilateral pulmonary involvement despite having relatively mild symptoms. Lymphocytopenia and increased CRP level were the most common laboratory findings in these patients. About $20 \%$ of these patients had recent close contact with other COVID-19 patients, and the rest were community-acquired (15).

The following measures have been recommended to manage elderly patients with COVID-19 in recent studies: (1) attention should be paid to the management of the possible comorbidities in addition to the antiviral therapy; (2) prevention of drugs interaction, especially in the case of fluoroquinolones; (3) precise adjustment of the dosage of the drugs based on creatinine clearance; (4) prevention of the intubation or extubation as soon as possible; (5) evaluation for secondary bacterial infections; and (6) repeated rehabilitation sessions and preventing the patients from delirium by mobilizing patients in the hospital as soon as possible (15-18). As the use of ACE inhibitors and angiotensin receptor blockers (ARBs) might lead to the increased expression of ACE2, some studies indicate that these drugs should not be prescribed in probable COVID19 patients, provided that other treatment options are available. Moreover, it is recommended in the literature not to prescribe thiazolidinedione and ibuprofen for COVID-19 patients (19-23). However, some other studies and reliable resources around the world indicated that ACE inhibitors and ARBs could be continued for the COVID-19 patients, as they used them before the disease, and since there is not enough evidence available yet on the disadvantages of taking these drugs by patients with COVID-19 (24, 25). More specific studies are needed on the side effects of ACE inhibitors and ARBs in the elderly patients with COVID-19. We have summarized our search results in defined timeline in the Table 1. 


\begin{tabular}{|c|c|c|c|c|c|c|c|c|}
\hline First Author & Country & Type of study & $\overline{S e x}$ & Age (years) & $\begin{array}{l}\text { Sample size } \\
(\mathrm{N})\end{array}$ & Most common symptoms & $\begin{array}{c}\text { Comorbidities; N (\%) } \\
\text { HTN } \cdot 5(2778)\end{array}$ & Prognosis \\
\hline Liu K (14) & China & $\begin{array}{l}\text { Retrospective } \\
\text { study }\end{array}$ & $\begin{array}{c}\text { F: } 6(33.3 \%) \\
\text { M: } 12(66.6 \%)\end{array}$ & $\begin{array}{c}\text { Median: } 68 \\
\text { (IQR: } 65.25-69.75)\end{array}$ & $\begin{array}{l}(\mathrm{N}) \\
18\end{array}$ & $\begin{array}{c}\text { Fever: } 14(77.78) \\
\text { Cough and sputum: } 6(33.33) \\
\text { Chest tightness, Difficulty breathing: } 2 \text { (11.11) } \\
\text { Fatigue: } 2 \text { (11.11) }\end{array}$ & $\begin{array}{c}\text { HTN: } 5(27.78) \\
\text { DM: } 3 \text { (16.67) } \\
\text { Cardiac Diseases: } 2 \\
(11.1)\end{array}$ & $\begin{array}{c}\text { ICU: } 4(22.22) \\
\text { Died: } 1(5.56) \\
\text { Health and discharge: } \\
17(94.44)\end{array}$ \\
\hline Lin $Y(15)$ & China & $\begin{array}{l}\text { Retrospective } \\
\text { study }\end{array}$ & $\begin{array}{l}\text { F: } 60(48.4 \%) \\
\text { M: } 64(51.6 \%)\end{array}$ & $\begin{array}{c}\text { Mean (SD): } \\
64.5(9.06)\end{array}$ & 124 & $\begin{array}{l}\text { Cough: } 58(47) \\
\text { Myalgia: } 40(32) \\
\text { Diarrhea: } 19(15)\end{array}$ & - & - \\
\hline Wu C (22) & China & $\begin{array}{l}\text { Retrospective } \\
\text { cohort study }\end{array}$ & $\begin{array}{l}\text { F: } 69(36.7) \\
\text { M: } 119(63.3)\end{array}$ & $\begin{array}{l}\text { Mean (SD): } \\
51.9(14.26)\end{array}$ & 188 & $\begin{array}{c}\text { Fever: } 174(92.6) \\
\text { Cough: } 157(83.5) \\
\text { Sputum: } 74(39.4) \\
\text { Chest distress or pain: } 63(33.5) \\
\text { Fatigue Myalgia: } 61(32.5)\end{array}$ & $\begin{array}{c}\text { HTN: } 38 \text { (20.2) } \\
\text { DM: } 20(10.6)\end{array}$ & $\begin{array}{c}\text { Discharged: } 145 \\
(77.1) \\
\text { ICU: } 50(26.6)\end{array}$ \\
\hline Yang X (59) & China & $\begin{array}{l}\text { Retrospective } \\
\text { study }\end{array}$ & $\begin{array}{l}\text { F: } 17(33) \\
\text { M: } 35(67)\end{array}$ & $\begin{array}{l}\text { Mean (SD): } \\
59.7(13.3)\end{array}$ & 67 & $\begin{array}{l}\text { Fever: } 51(98) \\
\text { Cough: } 40(77) \\
\text { Myalgia: } 6(11.5) \\
\text { Headache: } 3(6)\end{array}$ & $\begin{array}{l}\text { HTN: } 3(5 \%) \\
\text { DM: } 2(10) \\
\text { Chronic pulmonary } \\
\text { disease: } 2(10)\end{array}$ & _- \\
\hline Guan W (60) & China & $\begin{array}{l}\text { Retrospective } \\
\text { study }\end{array}$ & $\begin{array}{l}\text { F: } 22(32.8) \\
\text { M: } 45(67.2)\end{array}$ & $\begin{array}{l}\text { Median: } 63 \\
\text { (IQR: 53- 71) }\end{array}$ & & $\begin{array}{c}\text { Fever: } 24(35.8) \\
\text { Cough: } 46(68.7) \\
\text { Sputum: } 20(29.9) \\
\text { Headache: } 8(11.9) \\
\text { Diarrhea: } 4(6) \\
\text { Fatigue: } 22(32.8) \\
\text { Myalgia: } 6(9)\end{array}$ & $\begin{array}{c}\text { HTN: } 24(35.8) \\
\text { DM: } 18 \text { (26.9) } \\
\text { Chronic pulmonary } \\
\text { disease: } 7 \text { (10.4) } \\
\text { CHD: } 6(9) \\
\text { Cerebrovascular } \\
\text { disease: } 4(6) \\
\text { Cancer: } 1(1.5)\end{array}$ & $\begin{array}{c}\text { ICU: } 55(82.1) \\
\text { Discharge from } \\
\text { hospital: } 1(1.5) \\
\text { Death: } 15(22.4) \\
\text { Recovery: } 2(1.2) \\
\text { Hospitalization: } 51 \\
\quad(76.1)\end{array}$ \\
\hline
\end{tabular}


Organ systems in elderly patients with COVID-19

Pulmonary system complications

SARS-CoV-2 interacts with the ACE2 receptor. ACE2 receptor is highly expressed in the alveoli, bronchial epithelium, and vascular endothelium. Binding of the SARSCoC-2 to the ACE2 receptor triggers a cascade of further events leading to acute injury of the pulmonary system and pulmonary edema $(26,27)$. In addition, the cytokine storm, which is a common complication of COVID-19, can worsen the acute impaired respiratory function, especially in critically ill patients $(28,29)$. Conditions like senile emphysema and muscular atrophy might lead to impaired lung function. Weakened respiratory function combined with decreased airway clearance as well as pulmonary reservation and the overall weaker immune system in the aged population than the younger individuals; make them more susceptible to a severe infection with SARS-CoV-2.

\section{Cardiovascular system complications}

The first carditis associated with Coronavirus was reported in 1980 (29). As further studies were performed, coronaviruses were found to be not common but undeniable potential pathogens for cardiac injury $(30,31)$. In heart diseases, the expression of ACE2 is relatively high, which could be associated with cardiac injury in the COVID-19 patients. Also, injury to the myocardial cells might be secondary to the impaired respiratory function and hypoxia in these patients (24).

Another concerning issue in elderly patients is the cardiotoxicity associated with antiviral therapies. They might trigger conditions like sick sinus syndrome and Q-T interval prolongation or lead to torsade de pointes by interacting with other drugs (32-34). Chloroquine, which is approved by the FDA to be prescribed for the severe cases of COVID-19 (35), could also cause Q-T interval prolongation, ventricular arrhythmias, and torsade de pointes, especially in high doses or administrating concurrently with ritonavir/lopinavir. Thus, it should be administered with caution in patients with a history of ventricular arrhythmia with bradycardia (heart rate $<50$ ), hypo magnesia $(\mathrm{Mg}<3 \mathrm{mg} / \mathrm{dL})$, and hypokalemia $(\mathrm{K}<4 \mathrm{meq} / \mathrm{l})$. For patients with a history of arrhythmia, atazanavir/ritonavir can be administered instead of lopinavir/ritonavir (Kaletra) (36). This combination is recommended to be used and continued in COVID-19 patients, and it is thought to stimulate the immune system (37).

\section{Liver function impairment}

Impaired liver function in COVID-19 patients might be a result of the direct effect of the virus on the hepatic cells. Liver function might also be impaired due to the side effect of medications used in the treatment regimen of the patients. Moreover, cytokine storm and hypoxia resulted from pneumonia might be another mechanism of liver injury. The impaired liver function in mild cases of COVID-19 is usually transient and could be resolved without a sequela (38).

Studies showed that the level of liver enzymes might abnormally alter in the SARS-CoV-2 infection. A study published on March 5, 2020, elevated 148 confirmed COVID-19 patients in the case of liver function tests, and showed $35.1 \%, 21.6 \%, 18.2 \%, 17.6 \%, 4.1 \%$ of patients had an abnormal level of LDH, AST, ALT, GGT, ALP, respectively. Also, $50.7 \%$ of these patients had some degree of hepatic impairment at the time of hospitalization, while some patients developed functional liver impairment after hospitalization. In this study, patients' medications were evaluated. It was indicated that the prescription of lopinavir/ritonavir was $25 \%$ higher in patients with abnormal laboratory liver function tests compared to the group of patients with normal tests. Since liver dysfunction might cause serious consequences and is associated with impaired immune function and increases the length of hospital stay, especially in elderly patients with multiple comorbidities, this study suggested further studies to replace the use of lopinavir/ritonavir in COVID-19 patients (39). Another study on the effect of lopinavir/ritonavir found that this regimen had no significant effect on the reverse conversion rate of SARS-CoV-2 (40). On the other hand, studies showed a higher efficacy of remdesivir over lopinavir/ritonavir in combination with interferon (2). Thus, the therapeutic regimen could be revised.

In the case of chronic liver disease, such as chronic hepatitis B or autoimmune disease, attention should be paid to a history of immunosuppression in patients with COVID19. In patients with a history of bile duct stenosis, the stenotic effects of the virus on the ducts should be considered (38). In elderly patients, special attention should be paid to the medications that have a hepatic mechanism and the inhibitory or activator effects on the liver function, especially in polypharmacy patients or patients with a history of hepatic disease. Drug interactions are also a notable concern which might lead to liver dysfunction and should be avoided.

\section{Renal system complications}

Researchers have found that kidneys' function decreases significantly by aging. On average, the glomerular filtration rate (GFR) is known to decrease by about $1 \mathrm{~mL}$ per minute per year from the age of $30(41,42)$. Equations for GFR estimation, which include age demographic parameters and serum creatinine levels, are available elsewhere and are widely used clinically and in research studies (43, 44). Accordingly, the filtration rate is reduced by almost $10 \mathrm{~mL} / \mathrm{min}$ each decade, so a healthy 70-year-old might have some degrees of renal dysfunction, which in turn increases the risk of drug toxicity and water and electrolyte disturbances. Adequate hemodynamic support and not using nephrotoxic drugs are of great importance to prevent elderly patients from renal impairment, considering that the early renal replacement therapy might improve patients' prognosis in patients with renal dysfunction.

Chloroquine and lopinavir/ritonavir, which are commonly used in the treatment regimen of COVID-19 patients, do not require dose adjustment based on the creatinine clearance. Some medications might be used as prophylaxis for secondary bacterial infection, such as fluoroquinolone and cephalosporin. These drugs require dose adjustment based on creatinine clearance (45). Also, in elderly patients, special attention should be paid to the polypharmacy and drug interactions, especially for cardiac 
drugs; namely, warfarin and digoxin, and other medications such as psychoactive agents and mood stabilizers (45). In patients with hypertension, due to the lack of data on the effect of calcium channel blockers on ACE2, changing ACE inhibitors to these drugs may be reasonable (20).

\section{Skin disorders}

The most common skin issues during the COVID-19 pandemic are mostly secondary to repeated contacts with disinfectants, sanitizers, soaps, and detergents. This issue is more commonly referred to as contact dermatitis or exacerbation of previous xerosis and asteatotic eczema. In severe cases, it might lead to defects of the skin barrier and cause secondary conditions. Exacerbations of previous skin conditions, such as rosacea, eczema, atopic dermatitis, neurodermatitis, which are common in elderly individuals, have also been reported in some COVID-19 patients. As the emotional stress during the outbreak might exacerbate these conditions or result in emergence of herpes reactivation, zona, telogen effluvium, alopecia areata, and psychocutaneous disorders, medical and psychological counseling could be helpful for these patients, especially elderly individuals in the quarantine. These sessions could be held online or through the media. The routine use of immunomodulators might increase the risk of developing COVID-19 or increase the risk of secondary and opportunistic infections, especially in elderly individuals. Also, due to usual multiple drug consumptions, it is more probable to encounter drug reactions or interactions during COVID-19 course in this age group. The long-term use of facial masks could also lead to facial acne and rosacea during the pandemic. Finally, during the pandemic, unnecessary visits, especially for cosmetic purposes, such as injection of fillers or Botox, should be strictly forbidden (46).

\section{Diabetes and elderly patients with COVID-19}

One of the most common diseases in the elderly individuals is diabetes, which is also a common comorbidity associated with COVID-19. Also, diabetes was a serious condition associated with higher rates of mortality in MERS, SARS, and H1N1 influenza (47-49). In a recent meta-analysis, the prevalence of diabetes was estimated at $9.7 \%$ in hospitalized patients $(50)$.

In elderly patients with diabetes, regular exercise and also regular adjustment of the blood sugar, healthy eating habits, increased protein intake, and correcting the vitamins and minerals deficiencies strengthen the immune system; the better the immune response, the milder the disease. It also decreases secondary infections. Elderly patients should not be norm glycemic, but glucose should be targeted and treated based on the underlying disease, performance level, and age. Insulin is the best controller for diabetes in bedridden patients (51). Antihypertensive drugs that cause decreased water volume, such as thiazolidinediones, should be avoided.

At the time of hospitalization, attention should be paid to the hyperglycemic effects of corticosteroids, since the stress and inflammatory response caused by COVID-19 can increase the secretion of endogenous corticosteroid hormones. It can cause a fluctuation in the blood sugar in patients with COVID-19. Therefore, the precise chart for the blood sugar for 4 weeks after discharge is needed (52). In diabetic patients with diabetic retinopathy or in patients predisposed to mattered retinopathy, there are several guidelines for statins. Special attention should also be paid to pigmentosa retinitis and the ocular side effects of hydroxychloroquine (53).

\section{Special points}

\section{Long-term care centers for elderly individuals}

The consequences of possible epidemics in long-term care centers could be very severe in the case of an elderly population who are immunologically more susceptible to COVID-19 infection. Therefore, limiting the risk of the outbreak of COVID-19 in care centers for elderly individuals is of significant importance. More robust quarantine measures should be adopted by employees who live in high-risk areas or in close contact with probable cases. In the event of any suspected COVID-19 infection, rapid transfer to a specialist center as soon as possible is highly important. While waiting to be transported to the hospital, the patient should be placed in a single isolated room. Wearing a mask (N95 or FFP2 for the patient and also the health care staff) and careful hand hygiene are critical preventive measures to limit the emission of the disease. Health care personnel should also wear eye shields and use disposable gloves and gowns regularly to provide optimal levels of protection (54).

\section{Social isolation and elderly individuals}

Due to the COVID-19 pandemic and the social distancing and quarantine measures, dealing with the elderly individuals who are high-risk and more susceptible to the consequences of this pandemic is a great concern in the health care systems all around the world. These individuals are also more vulnerable to cardiovascular problems, autoimmune diseases, neurocognitive disorders, and mental health issues (55). Social distancing might force the elderly individuals to depression and anxiety (55). Elderly patients, especially those who have no close family and only rely on volunteer or social services, are more susceptible to mental isolation during the pandemic and quarantine. Online technologies might help social support for the aged people and also help them stay connected to the society and have a sense of belonging (56). The elderly should be taught to use new technologies and electronic devices. During the quarantine and social isolation, social contact with the elderly individuals should be maintained through some simple measures, such as frequent phone calls by friends and relatives and free access to health care counseling services via phone calls. Moreover, cognitive behavioral therapy sessions could be held online to reduce the sense of loneliness and improve the elderly individuals' mental health (57).

Health officials urge older people to stay home and avoid social contact with family and friends, which can make it difficult for them to get the food and medicine they need. Elderly people usually have little or no ability to deal with new technologies and software to order food and medicine online. This issue might be even more seri- 
ous in developing regions and rural areas. Furthermore, due to the strict quarantine measures and the heaver workload in health care facilities, household care for elderly patients and follow-up visits after their discharge from hospital are remarkably limited. Consequently, it is recommended not to discharge elderly patients from a hospital after resolving the symptoms, instead continuous care should be provided by the formal caregivers in residential housing or assisted living housing facilities based on the available services in each region (58).

Some clinical and therapeutic features of COVID-19 and its final sequels may become more clear and evident during time especially about cutaneous signs (61-63) and other organs not discussed in this review per detail; which needs more focus in future studies. Elective treatment of primarily cutaneous disorders or cutaneous presentations of systemic disorders especially in elderly people could be postponed in pandemic era; like cosmetic procedures, non-emergent surgeries or medical skin managements (64).

\section{Conclusion}

During the COVID-19 pandemic, elderly individuals are more susceptible to the consequences of the infection with SARS-CoV-2 than the younger individuals due to weaker immune systems and the presence of comorbidities and underlying conditions. Moreover, the quarantine and social isolation might trigger some other concerning conditions, such as depression and anxiety. The organ systems; namely, the pulmonary system, cardiovascular system, liver function, and renal system in elderly patients, are more vulnerable to the comorbidities during SARS-CoV-2 infection. Diabetes is also a common comorbidity in elderly patients and their blood sugar level should be carefully monitored even 4 weeks after discharge. Management of elderly patients with COVID-19 relies more on the preventive measures to reduce possible comorbidities in the mentioned organ systems. The lopinavir/ritonavir regimen has been found to interfere with normal liver function. Therefore, it should be replaced with other options such as remdesivir. Some medications need dose adjustment due to the renal function based on creatinine clearance, especially antibiotic, which might be used for the prophylaxis of secondary bacterial infections. Health care providers should consider drug reactions more carefully in the elderly patients due to polypharmacy. In addition, more attention should be paid to the mental health of elderly individuals during the quarantine. Social contact through online facilities, media, and phone calls should be maintained to ensure their mental health during this stressful situation. Also, they should be provided with enough food and medications by their families or friends. Also, providing social and volunteer services might play an important role in the mental health of those patients who have no social network. As the chance of multiorgan involvement is more common among elderly patients, multidisciplinary and holistic evaluations are required to reduce the consequences in the aged individuals of the society.

\section{Acknowledgement}

The authors would like to show their gratitude to Rasoul Akram Hospital Clinical Research Development Center (RCRDC) for its technical and editorial assists.

\section{Conflict of Interests}

The authors declare that they have no competing interests.

\section{References}

1. $\mathrm{Wu} \mathrm{Z}, \mathrm{McGoogan}$ JM. Characteristics of and important lessons from the coronavirus disease 2019 (COVID-19) outbreak in China: summary of a report of 31472 cases from the Chinese Center for Disease Control and Prevention. JAMA. 2020

2. WHO. Coronavirus disease (COVID-19) Pandemic. 2020.

3. Yang W, Cao Q, Qin L, Wang X, Cheng Z, Pan A, et al. Clinical characteristics and imaging manifestations of the 2019 novel coronavirus disease (COVID-19): A multi-center study in Wenzhou city, Zhejiang, China. J Infect. 2020;80(4):388-393.

4. Zhang JJ, Dong X, Cao YY, Yuan YD, Yang YB, Yan YQ, et al. Clinical characteristics of 140 patients infected with SARS-CoV-2 in Wuhan, China. Allergy. 2020.

5. Chen H, Guo J, Wang C, Luo F, Yu X, Zhang W, et al. Clinical characteristics and intrauterine vertical transmission potential of COVID19 infection in nine pregnant women: a retrospective review of medical records. Lancet. 2020;395(10226):809-15.

6. Singhal T. A review of coronavirus disease-2019 (COVID-19). Indian J Pediatr. 2020;87(4):281-286.

7. Wrapp D, Wang N, Corbett KS, Goldsmith JA, Hsieh C-L, Abiona O, et al. Cryo-EM structure of the 2019-nCoV spike in the prefusion conformation. Science. 2020;367(6483):1260-3

8. Zhou P, Yang X-L, Wang X-G, Hu B, Zhang L, Zhang W, et al. Discovery of a novel coronavirus associated with the recent pneumonia outbreak in humans and its potential bat origin. BioRxiv. 2020.

9. Pan XW, Da Xu HZ, Zhou W, Wang LH, Cui XG. Identification of a potential mechanism of acute kidney injury during the COVID-19 outbreak: a study based on single-cell transcriptome analysis. Intensive Care Med. 2020;46(6):1114-1116.

10. Zou X, Chen K, Zou J, Han P, Hao J, Han Z. Single-cell RNA-seq data analysis on the receptor ACE2 expression reveals the potentia risk of different human organs vulnerable to $2019-\mathrm{nCoV}$ infection. Front Med. 2020;14(2):185-192.

11. Sun P, Qie S, Liu Z, Ren J, Xi JJ. Clinical characteristics of 50466 patients with 2019-nCoV infection. medRxiv. 2020.

12. Huang C, Wang Y, Li X, Ren L, Zhao J, Hu Y, et al. Clinical features of patients infected with 2019 novel coronavirus in Wuhan, China. Lancet. 2020;395(10223):497-506.

13. Han R, Huang L, Jiang H, Dong J, Peng H, Zhang D. Early clinical and CT manifestations of coronavirus disease 2019 (COVID-19) pneumonia. AJR Am J Roentgenol. 2020;215(2):338-343.

14. Liu K, Chen Y, Lin R, Han K. Clinical features of COVID-19 in elderly patients: A comparison with young and middle-aged patients. $\mathrm{J}$ Infect. 2020;80(6):e14-e18.

15. Lin, Yan and Ji, Chunlian and Weng, Weidong and $\mathrm{Xu}$, Pan and $\mathrm{Hu}$, Yijuan and Liang, Weiqing and Pu, Jinbao and Zhang, Hongjian, Epidemiological and Clinical Characteristics of 124 Elderly Outpatients with COVID-19 in Wuhan, China (2/20/2020). Available at SSRN: https://ssrn.com/abstract=3543596 or http://dx.doi.org/10.2139/ ssrn.3543596.

16. Yao TT, Qian JD, Zhu WY, Wang Y, Wang GQ. A systematic review of lopinavir therapy for SARS coronavirus and MERS coronavirus-A possible reference for coronavirus disease-19 treatment option. J Med Virol. 2020;92(6):556-563.

17 Zuo MZ, Huang YG, Ma WH, et al. Expert Recommendations for Tracheal Intubation in Critically ill Patients with Noval Coronavirus Disease 2019 [published online ahead of print, 2020 Feb 27]. Chin Med Sci J. 2020;35(2):105-109.

18. Xu J, Zhao S, Teng T, Abdalla AE, Zhu W, Xie L, et al. Systematic comparison of two animal-to-human transmitted human coronaviruses: SARS-CoV-2 and SARS-CoV. Viruses. 2020;12(2):244.

19. Wan Y, Shang J, Graham R, Baric RS, Li F. Receptor Recognition by the Novel Coronavirus from Wuhan: an Analysis Based on Decade- 


Long Structural Studies of SARS Coronavirus. J Virol.
2020;94(7):e00127-20.

20. Fang L, Karakiulakis G, Roth M. Are patients with hypertension and diabetes mellitus at increased risk for COVID-19 infection? [published correction appears in Lancet Respir Med. 2020 Jun;8(6):e54]. Lancet Respir Med. 2020;8(4):e21.

21. Xu Z, Shi L, Wang Y, et al. Pathological findings of COVID-19 associated with acute respiratory distress syndrome [published correction appears in Lancet Respir Med. 2020 Feb 25;:]. Lancet Respir Med. 2020;8(4):420-422.

22. Wu C, Hu X, Song J, Du C, Xu J, Yang D, et al. Heart injury signs are associated with higher and earlier mortality in coronavirus disease 2019 (COVID-19). medRxiv. 2020.

23. Sakabe M, Yoshioka R, Fujiki A. Sick sinus syndrome induced by interferon and ribavirin therapy in a patient with chronic hepatitis C. J Cardiol Cases. 2013;8(6):173-175.

24. Zheng YY, Ma YT, Zhang JY, Xie X. COVID-19 and the cardiovascular system. Nat Rev Cardiol. 2020;17(5):259-260.

25. Sparks MA, H.S. The Coronavirus Conundrum: ACE2 and Hypertension Edition. March17, 2020; Available from: http://www.nephjc.com/news/covidace.2.

26. Zhou P, Yang XL, Wang XG, Hu B, Zhang L, Zhang W, et al. A pneumonia outbreak associated with a new coronavirus of probable bat origin. Nature. 2020;579(7798):270-3.

27. Li W, Moore MJ, Vasilieva N, Sui J, Wong SK, Berne MA, et al. Angiotensin-converting enzyme 2 is a functional receptor for the SARS coronavirus. Nature. 2003;426(6965):450-4.

28. Heymann DL, Shindo N. COVID-19: what is next for public health? The Lancet. 2020;395(10224):542-5.

29. Luo W, Yu H, Gou J, Li X, Sun Y, Li J, et al. Clinical pathology of critical patient with novel coronavirus pneumonia (COVID-19). Pathology \& Pathobiology. Preprints 2020, 2020020407

30. Riski H, Hovi T, Frick MH. Carditis associated with coronavirus infection. Lancet. 1980;2(8185):100-101.

31. Alhogbani T. Acute myocarditis associated with novel Middle East respiratory syndrome coronavirus. Ann Saudi Med. 2016;36(1):78-80.

32. Elkind, M.S., R.A. Harrington, and I.J. Benjamin, Role of the American Heart Association in the Global COVID-19 Pandemic. Am Heart Assoc. 2020.

33. Kitahara K, Nakamura Y, Tsuneoka Y, et al. Cardiohemodynamic and electrophysiological effects of anti-influenza drug oseltamivir in vivo and in vitro. Cardiovasc Toxicol. 2013;13(3):234-243.

34. Chaubey SK, Sinha AK, Phillips E, Russell DB, Falhammar H. Transient cardiac arrhythmias related to lopinavir/ritonavir in two patients with HIV infection. Sex Health. 2009;6(3):254-257.

35. Tallei TE, Tumilaar SG, Niode NJ, Fatimawali F, Kepel BJ, Idroes R, et al. Potential of Plant Bioactive Compounds as SARS-CoV-2 Main Protease (Mpro) and Spike (S) Glycoprotein Inhibitors: A Molecular Docking Study. Preprints 2020, 2020040102 (doi: 10.20944/preprints202004.0102.v1).

36. Karimi A, Rafiei Tabatabaei S, Rajabnejad M, Pourmoghaddas Z, Rahimi H, Armin S, et al. An Algorithmic Approach to Diagnosis and Treatment of Coronavirus Disease 2019 (COVID-19) in Children: Iranian Expert's Consensus Statement. Arch Pediatr Infect Dis. In Press(In Press):e102400.

37. Massachusetts General Hospital COVID-19. Treatment Guidance, M.G. Hospital, Editor. 2020.

38. Zhang C, Shi L, Wang FS. Liver injury in COVID-19: management and challenges. Lancet Gastroenterol Hepatol. 2020;5(5):428-430.

39. Fan Z, Chen L, Li J, et al. Clinical Features of COVID-19-Related Liver Functional Abnormality. Clin Gastroenterol Hepatol. 2020;18(7):1561-1566.

40. Chen J, Ling Y, Xi X, Liu P, Li F, Li T, et al. Efficacies of lopinavir/ritonavir and abidol in the treatment of novel coronavirus pneumonia. Chin J Infect Dis. 2020;38(00).

41. Zhou XJ, Rakheja D, Yu X, Saxena R, Vaziri ND, Silva FG. The aging kidney. Kidney Int. 2008;74(6):710-720.

42. Rowe JW. Aging and renal function. Ann Rev Gerontol Geriatr. 1980;1(1):161-79.

43. Rule AD, Larson TS, Bergstralh EJ, Slezak JM, Jacobsen SJ, Cosio FG. Using serum creatinine to estimate glomerular filtration rate: accuracy in good health and in chronic kidney disease. Ann Intern Med. 2004;141(12):929-937.

44. Anderson AH, Yang W, Hsu CY, et al. Estimating GFR among participants in the Chronic Renal Insufficiency Cohort (CRIC) Study. Am
J Kidney Dis. 2012;60(2):250-261.

45. Luderer JR, Patel IH, Durkin J, Schneck DW. Age and ceftriaxone kinetics. Clin Pharmacol Ther. 1984;35(1):19-25.

46. Zheng Y, Lai W. Dermatology staff participate in fight against Covid-19 in China. J Eur Acad Dermatol Venereol. 2020;34(5):e210e211.

47. Yang JK, Feng Y, Yuan MY, et al. Plasma glucose levels and diabetes are independent predictors for mortality and morbidity in patients with SARS. Diabet Med. 2006;23(6):623-628.

48. Schoen K, Horvat N, Guerreiro NFC, de Castro I, de Giassi KS Spectrum of clinical and radiographic findings in patients with diagnosis of H1N1 and correlation with clinical severity. BMC Infect Dis. 2019;19(1):964.

49. Song Z, Xu Y, Bao L, Zhang L, Yu P, Qu Y, et al. From SARS to MERS, thrusting coronaviruses into the spotlight. Viruses. 2019;11(1):59.

50. Li B, Yang J, Zhao F, et al. Prevalence and impact of cardiovascular metabolic diseases on COVID-19 in China. Clin Res Cardiol. 2020;109(5):531-538

51. Gupta R, Ghosh A, Singh AK, Misra A. Clinical considerations for patients with diabetes in times of COVID-19 epidemic. Diabetes Metab Syndr. 2020;14(3):211-212.

52. Wang A, Zhao W, Xu Z, Gu J. Timely blood glucose management for the outbreak of 2019 novel coronavirus disease (COVID-19) is urgently needed. Diabetes Res Clin Pract. 2020;162:108118.

53. Browning DJ. Hydroxychloroquine and chloroquine retinopathy: screening for drug toxicity. Am J Ophthalmol. 2002;133(5):649-656.

54. Garnier-Crussard A, Forestier E, Gilbert T, Krolak-Salmon P. Novel Coronavirus (COVID-19) Epidemic: What Are the Risks for Older Patients?. J Am Geriatr Soc. 2020;68(5):939-940.

55. Gerst-Emerson K, Jayawardhana J. Loneliness as a public health issue: the impact of loneliness on health care utilization among older adults. Am J Public Health. 2015;105(5):1013-1019.

56. Newman MG, Zainal NH. The value of maintaining social connections for mental health in older people. Lancet Public Health 2020;5(1):e12-e13.

57. Armitage R, Nellums LB. COVID-19 and the consequences of isolating the elderly. Lancet Public Health. 2020;5(5):e256.

58. Zumla A, Hui DS, Azhar EI, Memish ZA, Maeurer M. Reducing mortality from 2019-nCoV: host-directed therapies should be an option. Lancet. 2020;395(10224):e35-e6.

59. Yang X, Yu Y, Xu J et al. Clinical course and outcomes of critically ill patients with SARS-CoV-2 pneumonia in Wuhan, China: a singlecentered, retrospective, observational study. Lancet Resp Med. 2020;8:475-81.

60. Huang C, Wang Y, Li X, et al. Clinical features of patients infected with 2019 novel coronavirus in Wuhan, China [published correction appears in Lancet. 2020 Jan 30;:]. Lancet. 2020;395(10223):497-506.

61. Seirafianpour F, Mozafarpoor S, Fattahi N, et al. Treatment of COVID-19 with pentoxifylline: Could it be a potential adjuvant therapy? [published online ahead of print, 2020 May 30]. Dermatol Ther. 2020; 13733

62. Nobari NN, Goodarzi A. Patients with specific skin disorders who are affected by COVID-19: What do experiences say about management strategies? A systematic review [published online ahead of print, 2020 Jun 18]. Dermatol Ther. 2020;e13867.

63. Seirafianpour F, Sodagar S, Pour Mohammad A, et al. Cutaneous manifestations and considerations in COVID-19 pandemic: A systematic review [published online ahead of print, 2020 Jul 8]. Dermatol Ther. 2020;e13986. Dermatol Ther. 2020;10.1111/dth.13986.

64. Ehsani A, Noormohammadpour P, Goodarzi A, et al. Comparison of long-pulsed alexandrite laser and topical tretinoin-ammonium lactate in axillary acanthosis nigricans: A case series of patients in a beforeafter trial. Caspian J Intern Med. 2016;7(4):290-293. 